\title{
Clostridium difficile and methicillin-resistant Staphylococcus aureus shedding by slaughter-age pigs
}

\author{
J Scott Weese ${ }^{1 *}$, Joyce Rousseau', Anne Deckert², Sheryl Gow ${ }^{3,4}$ and Richard J Reid-Smith ${ }^{2}$
}

\begin{abstract}
Background: Clostridium difficile and methicillin-resistant Staphylococcus aureus are critical human pathogens and of increasing concern in food animals. Because of the apparent impact of age on prevalence of these organisms, studies of slaughter age pigs are important when considering the potential for contamination of food. This study evaluated C. difficile and MRSA shedding by slaughter age pigs from farms across Canada.

Results: Clostridium difficile was isolated from 30/436 (6.9\%) samples from 15/45 (33\%) farms. After adjusting for clustering at the herd level, the prevalence was 3.4\%. Ribotype 078 (toxinotype V, North American Pulsotype 7) was the most common strain, accounting for $67 \%$ of isolates. MRSA was isolated from 21/460 (4.6\%) pigs from 5/46 (11\%) farms. The prevalence in pigs after adjusting for clustering at the herd level was $0.2 \%$. Seven different spa types were identified, with 3 related spa types (t011, t034, new) accounting for 16 (76\%) consistent with ST398 predominating.

Both MRSA and C. difficile samples were collected from 45 farms. Both MRSA and C. difficile were detected on 2 (4.4\%), with C. difficile only on 13 (29\%), MRSA only on 3 (6.7\%) and neither on 27 (60\%).

Conclusions: The prevalence of $C$. difficile and MRSA in slaughter age pigs was relatively low, particularly in comparison with studies involving younger pigs. The predominance of C. difficile ribotype 078 and MRSA ST398 was not surprising, but there was diversity in strain types and the majority of isolates of both organisms were strains that can be found in humans. While the prevalence of $C$. difficile and MRSA in slaughter age pigs was relatively low, there is clearly potential for contamination of meat from healthy pigs carrying this pathogen into slaughterhouses.
\end{abstract}

\section{Background}

Clostridium difficile and methicillin-resistant Staphylococcus aureus are important causes of disease in humans and of increasing concern in food animals. In pigs, $C$. difficile infection (CDI) can cause severe enteritis in young (1-7d old) piglets, often with high mortality [1-3]. Human CDI appears to be increasing in incidence and severity internationally [4-6]. Additionally, while once considered mainly a hospital-associated pathogen, community-associated CDI (CA-CDI) appears to be increasing $[7,8]$ and toxinotype $\mathrm{V}$ strains, particularly ribotype 078, appear to be over-represented in CA-CDI $[9,10]$. These strains have predominated in studies of pigs and

\footnotetext{
* Correspondence: jsweese@uoguelph.ca

'Dept of Pathobiology, University of Guelph, Guelph, Ontario, Canada Full list of author information is available at the end of the article
}

cattle [11-16] and have been found in retail meat $[17,18]$, raising concerns that $C$. difficile might be a zoonotic and foodborne infection $[13,19,20]$. Highly variable (0-52\%) shedding rates have been reported in studies of healthy pigs $[12,15,16,21,22]$. However, studies reporting high prevalences have involved young piglets and there is evidence of a significant impact of age on $C$. difficile shedding $[15,23]$. Evaluation of food contamination risks requires an understanding of the prevalence of $C$. difficile shedding and the $C$. difficile types shed by slaughter-age pigs, not piglets.

Similarly, methicillin-resistant Staphylococcus aureus (MRSA) was once predominantly a hospital-associated pathogen in humans, but has emerged as an important community-associated pathogen internationally. Recently, livestock-associated MRSA (LA-MRSA),

\section{() Biomed Central}


caused by sequence type 398 (ST398) strains [24-26], has emerged as an important public health issue, particularly in Europe. MRSA colonization has been identified in healthy pigs from various countries, sometimes at high rates [25-30]. Similarly, high MRSA colonization rates have been reported in pig farmers [29,31,32], and associations between pig contact and both MRSA infection and MRSA colonization in humans have been reported [33-38]. MRSA has also been identified in retail meat [39-41], heightening concerns but currently with unclear public health significance.

Prevalence studies have been reported for different pig populations in different regions, with prevalence ranging from 1 to $80 \%[25,28,30,42,43]$. As with C. difficile, there is evidence of age-related changes in MRSA colonization rates [44] and study of pigs at the age of slaughter is most relevant for assessment of food contamination issues. Studies involving commingled pigs, pigs at slaughterhouses or from multiple farms from the same production systems have been performed $[28,30]$, but could introduce effects of clustering or transient contamination from transportation and may therefore not provide an optimal estimate of true population prevalence. For these reasons, studies of non-commingled pigs close to the age of slaughter from a large number of unassociated farms are required to obtain a better estimate of the prevalence of MRSA colonization in pigs that are ready to enter the food chain.

The objectives of this study were to determine the prevalence of $C$. difficile and MRSA shedding by slaughter-age pigs on farms across Canada and to characterize recovered isolates.

\section{Methods}

\section{Study Population and Sample Collection}

Commercial swine farms from across Canada were recruited in conjunction with the Canadian Integrated Program for Antimicrobial Resistance Surveillance (CIPARS). This program has a network of farms and veterinarians across Canada that participate in ongoing surveillance and periodic research studies. Veterinarians participating in CIPARS were contacted and asked to recruit herds. On each participating farm, freshly passed fecal samples were collected from pens containing grower-finisher pigs close to the time of slaughter. A single sample was collected per pen, to represent an individual pig sample. The target was 10 pens per farm, however on some farms, 10 separate pens were not available so a smaller number of samples was obtained. Additionally, nasal swabs were collected from 10 noncomingled grower-finisher pigs that were close to slaughter age. Fecal and nasal samples were not necessarily collected from the same pigs, so $C$. difficile and MRSA were analysed independently.

\section{Clostridium difficile isolation}

Approximately $1 \mathrm{~g}$ of feces was inoculated into $9 \mathrm{ml}$ of C. difficile agar base (Oxoid Company, Nepean, Canada) with $C$. difficile moxalactam norfloxacin supplement (Oxoid Company, Nepean, Canada)(CDMN) and 0.1\% sodium taurocholate and incubated anaerobically at $37^{\circ}$ $\mathrm{C}$ for 7 days. An aliquot of the broth was alcohol shocked with an equal volume of anhydrous ethanol for 1 hour. This mixture was then centrifuged for $10 \mathrm{~min}$ at $4000 \mathrm{rpm}$. The supernatant was discarded and the pellet was streaked onto a CDMN agar plate and incubated anaerobically at $37^{\circ} \mathrm{C}$ for $48 \mathrm{~h}$. Suspicious colonies were subcultured onto blood agar and confirmed as C. difficile by Gram stain appearance, colony morphology, characteristic odor and production of l-proline aminopeptidase.

\section{Clostridium difficile isolate characterization}

Isolates were typed by PCR ribotyping as has been described elsewhere [45]. In situations where the ribotype was known to be a recognized international ribotype through previous typing of reference strains from the PHLS Anaerobic Reference Unit (Cardiff, UK), the appropriate numerical designation (i.e. 078) was used. Otherwise, internal nomenclature was used. Genes encoding production of toxins $\mathrm{A}(t c d A)$ and $\mathrm{B}(t c d B)$ were evaluated using PCR $[46,47]$. Detection of CDT (binary toxin) was performed using PCR directed at $c d t B$, the binding component [48]. Toxinotyping [49] and pulsed field gel electrophoresis (PFGE) [50] were performed on a representative of each toxigenic ribotype. Sequence analysis of $t c d C$ was performed and interpreted as previously described [51].

\section{MRSA Isolation}

Nasal swabs were inoculated into $9 \mathrm{ml}$ of enrichment broth consisting of $10 \mathrm{~g}$ tryptone/L, $75 \mathrm{~g}$ sodium chloride/L, $10 \mathrm{~g}$ mannitol/L and $2.5 \mathrm{~g}$ of yeast extract/L. After $24 \mathrm{~h}$ incubation at $35^{\circ} \mathrm{C}, 50 \mathrm{ul}$ of broth was inoculated onto MRSA Chromogenic agar (BBL CHROMagar MRSA, Becton, Dickinson and Company, Sparks, MD). Plates were incubated at $35^{\circ} \mathrm{C}$ and read after 24 and 48 h. Isolates were identified as $S$. aureus by colony morphology, Gram stain appearance, catalase reaction, coagulase reaction and $S$. aureus latex agglutination test (Pastorex Staph-plus, Bio-Rad, France). Methicillin-resistance was confirmed by penicillin binding protein $2 \mathrm{a}$ latex agglutination test (MRSA latex agglutination test, Oxoid Ltd., Hants, UK).

\section{MRSA Isolate Characterization}

Isolates were typed by sequencing of the $\mathrm{x}$ region of the protein A gene (spa typing) [52] and classified using the Ridom system (http://www.spaserver.ridom.de). Real 
time PCR was used to detect the $l u k F$ and $l u k S$ components of the Panton-Valentine leukocidin (PVL) [53]. Positive and negative controls were performed with each PCR run.

\section{Statistical Analysis}

The crude prevalence was calculated for both $C$. difficile and MRSA. The prevalence was then adjusted for clustering at the herd level using Generalized Linear and Latent Mixed Models (GLAMM) with adaptive quadrature (Stata Intercooled version 10.1, Stata Corporation, College Station, Texas, USA). Chi-squared test was used to compare the herd level prevalence between provinces. A $P$ value of $<0.05$ was considered significant.

This study was approved by the University of Guelph Animal Care Committee.

\section{Results}

\section{Clostridium difficile}

Clostridium difficile was isolated from 30/436 (6.9\%) samples from 15/45 (33\%) farms (Table 1). The prevalence after adjustment for clustering at the herd level was $3.4 \%$. Five to 10 samples were collected per farm (median 10). There was a significant difference between provinces at the farm level $(P=0.002)$, with the farm prevalence ranging from $0-100 \%$. On positive farms, between 1 and 5 samples (median $=1$ ), representing between $10-100 \%$ of samples, were positive.

Seven different ribotypes were identified (Table 2). Ribotype 078 isolates were classified as North American Pulsotype (NAP) 7 by PFGE. One additional toxinotype $\mathrm{V}$ ribotype was indistinguishable from NAP7 on PFGE, however the other toxinotype $\mathrm{V}$ ribotype (S6) had a PFGE pattern that is not consistent with any NAP type and had a 5 band difference from NAP7. Three of the 6 toxigenic ribotypes 3 (50\%), accounting for $82 \%$ of isolates, have been previously identified in humans in Canada [54].

On $7 / 15$ (47\%) positive farms, $C$. difficile was recovered from more than one pig. On 3 of these, all isolates were the same; ribotype 078 . On 2 farms, there was a combination of ribotype 078 and a single nontoxigenic isolate. On 2 other farms, ribotype 078 plus 1 or 2 other toxinotype $\mathrm{V}$ ribotypes were found. No disease attributed to $C$. difficile was reported on any of the participating farms.

\section{MRSA}

MRSA was isolated from $21 / 460$ (4.6\%) pigs from 5/46 (11\%) farms (Table 3). The prevalence in pigs after adjusting for clustering at the herd level was $0.2 \%$. The on-farm prevalence ranged from $0-70 \%$, with a range of $20-70 \%$ for positive farms. There was not a statistically significant difference in farm prevalence between provinces $(P=0.35)$

Seven different spa types were identified, corresponding to three different clones (Table 4). All isolates were PVL negative. Three related spa types (t011, t034, 04652), accounting for 16 (76\%) isolates were consistent with ST398. Three spa types, t002 ( $=2)$, t5518 $(n=1)$ and t067 ( $n=1)$ were consistent with Canadian epidemic MRSA-2 (CMRSA-2). One additional spa type (t064) was unrelated to the others and was consistent with CMRSA-5.

A single spa type was found on two farms, one with 7 t034 isolates and one with a single t002 isolate. On the 3 other farms, two or 3 different spa types were identified.

\section{Combined}

Both MRSA and C. difficile samples were collected from 45 farms. Both MRSA and C. difficile were detected on 2 (4.4\%), with C. difficile only on 13 (29\%), MRSA only on $3(6.7 \%)$ and neither on $27(60 \%)$.

\section{Discussion}

This study has identified a relatively low prevalence of both $C$. difficile and MRSA in pigs shortly before the time of slaughter. These data are consistent with recent studies demonstrating a significant impact of age on $C$. difficile colonization in pigs $[15,22,23,55]$, such a a longitudinal study that reported a $96 \%$ cumulative prevalence in young piglets, with colonization of $74 \%$ of piglets on day 2 of life but only $3.7 \%$ in the same piglets on day 62 [23], and a similar study in an integrated swine operation reported $C$. difficile shedding in $50 \%$ of suckling

Table 1 Prevalence of Clostridium difficile shedding by slaughter age pigs in $\mathbf{5}$ difference Canadian provinces.

\begin{tabular}{|c|c|c|c|c|}
\hline Province & Number of pigs & Unadjusted prevalence (\%) $(95 \% \mathrm{Cl})$ & Adjusted pig prevalence (\%), (95\% Cl) & Farm prevalence \\
\hline A & 100 & $4.0(1.5-10.2)$ & $3.0(0.5-15.9)$ & $3 / 11(27 \%)$ \\
\hline $\bar{B}$ & 50 & $26(15.7-39.8)$ & $26(15.7-39.8)$ & $5 / 5(100 \%)$ \\
\hline $\mathrm{C}$ & 100 & $4.0(1.5-10.2)$ & $4.0(1.5-10.2)$ & $4 / 10(40 \%)$ \\
\hline $\mathrm{D}$ & 106 & 0 & 0 & $0 / 11$ \\
\hline $\bar{E}$ & 80 & $11.3(6.0-20.2)$ & $3.0(0.2-31.4)$ & $3 / 8(38 \%)$ \\
\hline Total & 436 & $6.9(4.9-9.7)$ & $3.4(0.8-13.6)$ & $15 / 45$ (33\%) \\
\hline
\end{tabular}


Table 2 Clostridium difficile isolated from healthy slaughter age pigs in Canada.

\begin{tabular}{|c|c|c|c|c|c|c|c|}
\hline Ribotype & n (\%) & TT & PFGE & Toxin genes & $\operatorname{tcd} C$ & Farms & Provinces \\
\hline 078 & $20(67 \%)$ & V & NAP7 & $t c d A, t c d B, c d t B$ & 39 bp deletion, C184T mutation & 12 & $A, B, C, E$ \\
\hline 56 & $3(10 \%)$ & V & NAP7-like & $t c d A, t c d B, c d t B$ & 39 bp deletion, C184T mutation & 2 & $E$ \\
\hline $\mathrm{MOH}-\mathrm{S}$ & $2(6.7 \%)$ & 0 & Non-epidemic clone & $t c d A, t c d B$ & Wild-type & 1 & A \\
\hline $\mathrm{R}$ & $1(3.3 \%)$ & 0 & Non-epidemic clone & $t c d A, t c d B$ & Wild-type & 1 & $C$ \\
\hline 57 & $1(3.3 \%)$ & $\mathrm{V}$ & NAP7 & $t c d A, t c d B, c d t B$ & 39 bp deletion, C184T mutation & 1 & $E$ \\
\hline OVCAA & $1(3.3 \%)$ & 0 & Non-epidemic clone & $t c d A, t c d B$ & 18 bp deletion & 1 & A \\
\hline OVCJ & $2(6.7 \%)$ & NA & NT & None & NA & 2 & B \\
\hline
\end{tabular}

T: Toxinotype

NA: not applicable

NT: Not tested

piglets, but only $3.9 \%$ of grower-finisher pigs and breeding animals [15]. The reason for variation in prevalence with age has not been specifically evaluated but may relate to the poorly developed intestinal microflora in young pigs, with more competition from other microorganisms as the pig ages.

The relatively low farm- and pig-prevalence of MRSA was somewhat surprising, although some of the adjusted prevalence estimates had wide confidence intervals. These data are in contrast to a previous Canadian study that reported MRSA from 25\% of pigs (piglets, weaners, grower-finishers) and $45 \%$ of farms in Ontario, Canada [29], as well as some studies from other regions reporting colonization rates of 39-80\% [25,28,30]. However, results are similar to the report of isolation of MRSA from $1.3 \%$ of pigs in Switzerland at the time of slaughter [42], as well as $0.8 \%$ in weaned pigs in Malaysia [56]. As with $C$. difficile, there appears to be a significant impact of age on MRSA colonization in pigs, with MRSA colonization rates decreasing dramatically as pigs age [44], and this may account for the low prevalence reported here, perhaps because of changes in the nasal commensal microflora or immune response.

The inter-provincial difference in prevalence in $C$. difficile was unexpected. There were no readily apparent explanations, however specific farm management factors were not queried because of the relatively small farm sample size. Identification of factors that may influence differences in $C$. difficile between farms or between regions is important, in order to identify potential interventions for the reduction of $C$. difficile shedding.

Regardless of the reasons, the relatively low prevalence of $C$. difficile and MRSA in pigs approaching the time of slaughter may have implications for assessment of foodborne contamination. While the prevalence in young piglets may have pig-health implications (at least for $C$. difficile), the relevance for foodborne contamination is limited because young piglets are rarely slaughtered for food. The prevalence of $C$. difficile or MRSA in pigs at or shortly before the time of slaughter is presumably more relevant, and this study indicates a relatively low prevalence. Additionally, the potential for marked variation in prevalence simply as a factor of age must be considered in studies involving $C$. difficile and MRSA in pigs and likely other animal species.

Despite the relatively low prevalence, the potential for food as a source of $C$. difficile and MRSA for humans cannot be dismissed. Contamination of retail meat clearly can occur [17,39-41,57-59], but limited information is available regarding the origins of food contamination. Prospective studies of the slaughter and processing systems are required to determine the source, or sources, of contamination and identify potential interventions.

Clostridium difficile typing data were not particularly surprising. Ribotype 078, a toxinotype V strain, predominated, as has been previously reported in studies of pigs [12-14,21], but there were two other toxinotype $\mathrm{V}$

Table 3 Isolation of methicillin-resistant Staphylococcus aureus (MRSA) from slaughter-age pigs in Canada.

\begin{tabular}{lllll}
\hline Province & Number of farms, pigs & Unadjusted pig prevalence $(\mathbf{\%}, \mathbf{9 5} \% \mathbf{C l})$ & Adjusted pig prevalence (\%, 95\% Cl) & Farm prevalence \\
\hline A & 10,100 & 0 & 0 & 0 \\
\hline B & 5,50 & 0 & 0 & 0 \\
\hline C & 10,100 & $11(6.2-18.8)$ & $0.04(0.0-99.8)$ & $30 \%(3 / 10)$ \\
\hline D & 13,130 & $0.8(0.1-5.3)$ & $0.77(0.1-5.3)$ & $7.7 \%(1 / 13)$ \\
\hline E & 8,80 & $11.3(6.0-20.2)$ & $0.35(0-88.8)$ & $25 \%(2 / 8)$ \\
\hline Total & 46,460 & $4.6(3.0-6.9)$ & $0.002(0-12.8)$ & $13 \%(6 / 46)$ \\
\hline
\end{tabular}


Table 4 Typing data for methicillin-resistant Staphylococcus aureus (MRSA) isolated from slaughter-age pigs in Canada.

\begin{tabular}{|c|c|c|c|c|}
\hline Spa type & $\mathrm{n}$ & Repeat pattern & Farms & Province \\
\hline t011 & $8(38 \%)$ & 08-16-02-25-—————————-34-24-25 & 5,9 & C \\
\hline t034 & $7(33 \%)$ & $08-16-02-25-02-25---34-24-25$ & 28 & E \\
\hline t4652 & $1(4.8 \%)$ & 08-16-02-25-02-25—————- 24-25 & 9 & C \\
\hline t002 & $2(9.5 \%)$ & 26-23-17-34-17-——-20-17-12-17-16 & 13,24 & $\mathrm{D}, \mathrm{E}$ \\
\hline t5518 & $1(4.8 \%)$ & 26-23-17-34-17-23-——-17-12-17-16 & 5 & E \\
\hline t067 & $1(4.8 \%)$ & 26-23-17-34-17-——-20-17-12-17 & 5 & E \\
\hline t064 & $1(4.8 \%)$ & $11-19-12-05-17-34-24-34-22-25$ & 13 & $E$ \\
\hline
\end{tabular}

ribotypes. Non-ribotype 078 toxinotype V strains have been reported previously in pigs, particularly ribotype $066[12,16,21]$. Ribotype 066 was not identified in this study and the lack of a standard international system for identifying and naming uncommon ribotypes hampers comparison of uncommon isolates from different studies. It is, therefore, unclear whether the two non-ribotype 078/066 ribotypes identified here have been reported in pigs elsewhere. It is likely that these two strains are closely related to, and probably evolved from, ribotype 078. Alterations in $t c d C$, a gene that down regulates production of toxins $\mathrm{A}$ and $\mathrm{B}$ has been linked to hypervirulence in some $C$. difficile strains, particularly ribotypes 027 and $078[10,60]$, although the true role of this gene in virulence is still unclear. Ribotype 078, S6 and $\mathrm{S} 7$ possessed the expected 39 bp deletion and C184T nonsense mutation, providing further support to the suspicion that they are closely related.

Similarly, the predominance of spa types that correspond to ST398 was not unexpected, given the predominance of this clone in pigs in most regions [25,28,30,61]. However, while ST398 has accounted for virtually all isolates reported in pigs from many regions, other strains have been previously identified in pigs $[27,29]$. In this study, two human epidemic clones were identified. The first, CMRSA-2 (also known as USA100) is an ST5 strain that is the most common cause of hospital-associated MRSA infection in humans in Canada [62], as well as the most common strain found in colonized humans in the US [63]. It accounted for 14\% of isolates in an earlier study of pigs in Ontario [29] and 15\% in this study, but has not, to our knowledge, been reported in pigs elsewhere. Interestingly, this strain accounted for $29 \%$ and $100 \%$ of MRSA isolates recovered from pork in two recent studies of retail meat in Canada $[40,41]$. The other strain was spa type t064 that corresponds to CMRSA-5 (USA500), an ST8 strain that is a relatively uncommon human epidemic clone [63], but commonly reported in horses in some regions [29]. This strain has not, to our knowledge, been previously isolated from pigs, however it accounted for 38\% of MRSA isolates in a study of Canadian retail pork [41]. The presence of both livestock-associated and human epidemic clones suggests that there may be multiple routes of MRSA exposure in pigs, both from other pigs and from humans. ST398 MRSA can reasonably be assumed to have originated in livestock, although humans can carry this strain and could presumably pass it between pigs. The human epidemic clones found in pigs almost certainly were ultimately from humans, since parallel development of these strains in pigs is extremely unlikely. However, it is clear that both livestock associated and human MRSA clones can be transmitted within and between pigs and humans.

No pigs enrolled in this study had signs of clinical MRSA infection. While MRSA can cause disease in pigs [64], clinical infections appear to be quite rare, something that is positive from a pig health standpoint but which allows MRSA to be present undetected on farms.

Interestingly, the presence of both MRSA and C. difficile on a farm was uncommon, being identified in only $4.4 \%$ of farms. The reasons for this are unclear but since MRSA and $C$. difficile share various risk factors in humans (e.g. antimicrobial administration), it is somewhat surprising that there was no apparent association between the presence or absence of these two pathogens on farms.

\section{Conclusions}

Both $C$. difficile and MRSA were identified in a small percentage of pigs at the age of slaughter, consisting mainly of strains that are of concern for human health. The public health risk posed by $C$. difficile and MRSA in Canadian pigs is unclear, partly because of poor understanding of the role of livestock associated MRSA and $C$. difficile strains in community-associated disease in people in the country. ST398 MRSA infections in humans appear to be rare in Canada, although cases have been recently identified and there is concern that 
they could increase [65]. The presence of these two pathogens in pigs, albeit at relatively low prevalence, does not necessarily indicate a human health risk, either from direct contact or foodborne contamination, however it should not be dismissed. A better understanding of the epidemiology of $C$. difficile and MRSA in livestock and humans is required to help elucidate the role of animals in human infections and to identify possible interventions to reduce the potential public health impact of this important pathogen.

\section{Acknowledgements}

This study was supported by the Canadian Pork Council, Public Health Agency of Canada and the Canadian Integrated Program for Antimicrobial Resistance Surveillance (CIPARS). The authors thank Louise Bellai of the Public Health Agency of Canada for logistical support.

\section{Author details}

'Dept of Pathobiology, University of Guelph, Guelph, Ontario, Canada. ${ }^{2}$ Laboratory for Foodborne Zoonoses, Public Health Agency of Canada, Guelph, Ontario, Canada. ${ }^{3}$ Dept of Large Animal Clinical Sciences, University of Saskatoon, Saskatoon, Saskatchewan, Canada. ${ }^{4}$ Laboratory for Foodborne Zoonoses, Public Health Agency of Canada, Saskatoon, Saskatchewan, Canada.

\section{Authors' contributions}

JSW and RRS conceived the study, and JSW, AD, SG and RRS participated in study design. $A D$ and SG coordinated field sampling and communication with participating veterinarians. JR performed all laboratory studies. JSW, AD and SG analysed the data. JSW wrote the initial draft of the manuscript. All authors participated in manuscript review. All authors read and approved the final manuscript.

Received: 19 January 2011 Accepted: 26 July 2011

Published: 26 July 2011

\section{References}

1. Keel M, Songer J: The comparative pathology of Clostridium difficileassociated disease. Vet Pathol 2006, 43(3):225-240.

2. Songer J, Jones R, Anderson M, Barbara A, Post K, Trinh H: Prevention of porcine Clostridium difficile-associated disease by competitive exclusion with nontoxigenic organisms. Vet Microbiol 2007, 124:358-361.

3. Yaeger MJ, Kinyon JM, Glenn Songer J: A prospective, case control study evaluating the association between Clostridium difficile toxins in the colon of neonatal swine and gross and microscopic lesions. J Vet Diagn Invest 2007, 19(1):52-59.

4. Pépin J, Valiquette L, Alary M, Villemure P, Pelletier A, Forget K, Pépin $K$, Chouinard D: Clostridium difficile-associated diarrhea in a region of Quebec from 1991 to 2003: a changing pattern of disease severity. CMAJ 2004, 171(5):466-472.

5. Kuijper E, van den Berg R, Debast S, Visser C, Veenendaal D, Troelstra A, van der Kooi T, van den Hof S, Notermans D: Clostridium difficile ribotype 027, toxinotype III, the Netherlands. Emerg Infect Dis 2006, 12(5):827-830.

6. Goorhuis A, Van der Kooi T, Vaessen N, Dekker F, Van den Berg R, Harmanus C, van den Hof S, Notermans D, Kuijper E: Spread and epidemiology of Clostridium difficile polymerase chain reaction ribotype 027/toxinotype III in The Netherlands. Clin Infect Dis 2007, 45(6):695-703.

7. Centers for Disease Control and Prevention (CDC): Surveillance for community-associated Clostridium difficile-Connecticut, 2006. MMWR Morb Mortal Wkly Rep 2008, 57(13):340-343.

8. Paltansing S, van den Berg RJ, Guseinova RA, Visser CE, van der Vorm ER, Kuijper EJ: Characteristics and incidence of Clostridium difficile-associated disease in The Netherlands, 2005. Clin Microbiol Infect 2007, 13(11):1058-1064.

9. Goorhuis A, Bakker D, Corver J, Debast SB, Harmanus C, Notermans DW, Bergwerff AA, Dekker FW, Kuijper EJ: Emergence of Clostridium difficile infection due to a new hypervirulent strain, polymerase chain reaction ribotype 078. Clin Infect Dis 2008, 47(9):1162-1170.

10. Jhung M, Thompson A, Killgore G, Zukowski W, Songer G, Warny M, Johnson S, Gerding D, McDonald L, Limbago B: Toxinotype V Clostridium difficile in Humans and Food Animals. Emerging Infect Dis 2008, 14(7):1039-1045

11. Rodriguez-Palacios A, Stämpfli H, Duffield T, Peregrine A, Trotz-Williams $L$, Arroyo L, Brazier J, Weese J: Clostridium difficile PCR ribotypes in calves, Canada. Emerging Infect Dis 2006, 12(11):1730-1736.

12. Avbersek J, Janezic S, Pate M, Rupnik M, Zidaric V, Logar K, Vengust M, Zemljic M, Pirs T, Ocepek M: Diversity of Clostridium difficile in pigs and other animals in Slovenia. Anaerobe 2009, 15(6):252-255.

13. Debast $S B$, van Leengoed LA, Goorhuis A, Harmanus C, Kuijper EJ, Bergwerff AA: Clostridium difficile PCR ribotype 078 toxinotype $V$ found in diarrhoeal pigs identical to isolates from affected humans. Environ Microbiol 2009, 11(2):505-511.

14. Keel K, Brazier J, Post K, Weese S, Songer J: Prevalence of PCR ribotypes among Clostridium difficile isolates from pigs, calves, and other species. $J$ Clin Microbiol 2007, 45(6):1963-1964.

15. Norman KN, Harvey RB, Scott HM, Hume ME, Andrews K, Brawley AD: Varied Prevalence of Clostridium difficile in an Integrated Swine Operation. Anaerobe 2009, 15:256-260.

16. Pirs T, Ocepek M, Rupnik M: Isolation of Clostridium difficile from food animals in Slovenia. J Med Microbiol 2008, 57(Pt 6):790-792.

17. Songer JG, Trinh $H T$, Killgore GE, Thompson AD, McDonald LC, Limbago BM: Clostridium difficile in retail meat products, USA, 2007. Emerging Infect Dis 2009, 15(5):819-821.

18. Weese J, Avery B, Rousseau J, Reid-Smith R: Detection and enumeration of Clostridium difficile in retail beef and pork. Appl Environ Microbiol 2009.

19. Goorhuis A, Debast SB, van Leengoed LA, Harmanus C, Notermans DW, Bergwerff AA, Kuijper EJ: Clostridium difficile PCR ribotype 078: an emerging strain in humans and in pigs? J Clin Microbiol 2008, 46(3):1157.

20. Rupnik M: Is Clostridium difficile-associated infection a potentially zoonotic and foodborne disease? Clin Microbiol Infect 2007, 13(5):457-459.

21. Baker AA, Davis E, Rehberger T, Rosener D: Prevalence and diversity of toxigenic Clostridium perfringens and Clostridium difficile among swine herds in the midwest. Appl Environ Microbiol 2010, 76(9):2961-2967.

22. Alvarez-Perez S, Blanco JL, Bouza E, Alba P, Gibert X, Maldonado J, Garcia ME: Prevalence of Clostridium difficile in diarrhoeic and nondiarrhoeic piglets. Vet Microbiol 2009, 137:302-305.

23. Weese JS, Wakeford T, Reid-Smith R, Rousseau J, Friendship R: Longitudinal investigation of Clostridium difficile shedding in piglets. Anaerobe 2010, 16(5):501-504.

24. van Duijkeren E, Ikawaty R, Broekhuizen-Stins M, Jansen M, Spalburg E, de Neeling A, Allaart J, van Nes A, Wagenaar J, Fluit A: Transmission of methicillin-resistant Staphylococcus aureus strains between different kinds of pig farms. Vet Microbiol 2008, 126:383-389.

25. Huijsdens $X$, van Dijke B, Spalburg E, van Santen-Verheuvel M, Heck M Pluister G, Voss A, Wannet W, de Neeling A: Community-acquired MRSA and pig-farming. Ann Clin Microbiol Antimicrob 2006, 5:26.

26. Köck R, Harlizius J, Bressan N, Laerberg R, Wieler LH, Witte W, Deurenberg RH, Voss A, Becker K, Friedrich AW: Prevalence and molecular characteristics of methicillin-resistant Staphylococcus aureus (MRSA) among pigs on German farms and import of livestock-related MRSA into hospitals. Eur J Clin Microbiol Infect Dis 2009, 28:1375-1382.

27. Cui S, Li J, Hu C, Jin S, Li F, Guo Y, Ran L, Ma Y: Isolation and characterization of methicillin-resistant Staphylococcus aureus from swine and workers in China. J Antimicrob Chemother 2009, 64(4):680-683.

28. de Neeling A, van den Broek M, Spalburg E, van Santen-Verheuvel M, DamDeisz W, Boshuizen H, van de Giessen A, van Duijkeren E, Huijsdens X: High prevalence of methicillin resistant Staphylococcus aureus in pigs. Vet Microbiol 2007, 122(3-4):366-372.

29. Khanna T, Friendship R, Dewey C, Weese JS: Methicillin resistant Staphylococcus aureus colonization in pigs and pig farmers. Vet Microbiol 2007, 128:298-303.

30. Smith TC, Male MJ, Harper AL, Kroeger JS, Tinkler GP, Moritz ED, Capuano AW, Herwaldt LA, Diekema DJ: Methicillin-resistant Staphylococcus aureus (MRSA) strain ST398 is present in midwestern U.S. swine and swine workers. PLOS ONE 2008, 4(1):e4258.

31. Denis $\mathrm{O}$, Suetens $\mathrm{C}$, Hallin M, Catry B, Ramboer I, Dispas M, Willems G, Gordts B, Butaye P, Struelens MJ: Methicillin-resistant Staphylococcus 
aureus ST398 in swine farm personnel, Belgium. Emerging Infect Dis 2009, 15(7):1098-1101.

32. Voss A, Loeffen F, Bakker J, Klaassen C, Wulf M: Methicillin-resistant Staphylococcus aureus in pig farming. Emerging Infect Dis 2005 , 11(12):1965-1966.

33. Lewis HC, Mølbak K, Reese C, Aarestrup FM, Selchau M, Sørum M, Skov RL: Pigs as source of methicillin-resistant Staphylococcus aureus CC398 infections in humans, Denmark. Emerging Infect Dis 2008, 14(9):1383-1389.

34. van Rijen MM, Van Keulen PH, Kluytmans JA: Increase in a Dutch hospital of methicillin-resistant Staphylococcus aureus related to animal farming. Clin Infect Dis 2008, 46(2):261-263.

35. van den Broek IV, van Cleef BA, Haenen A, Broens EM, van der Wolf PJ, van den Broek MJ, Huiisdens X, Kluytmans J, van de Giessen AW, Tiemersma E: Methicillin-resistant Staphylococcus aureus in people living and working in pig farms. Epidemiol Infect 2008, 1-9.

36. van Rijen MM, Bosch T, Heck ME, Kluytmans JA: Meticillin-resistant Staphylococcus aureus epidemiology and transmission in a Dutch hospital. J Hosp Infect 2009, 72(4):299-306

37. Krziwanek K, Metz-Gercek S, Mittermayer H: Methicillin-Resistant Staphylococcus aureus ST398 from human patients, upper Austria. Emerging Infect Dis 2009, 15(5):766-769.

38. Van Cleef BAGL, Broens EM, Voss A, Huijsdens XW, Züchner L, Van Benthem BHB, Kluytmans JAJW, Mulders MN, van de Giessen AW: High prevalence of nasal MRSA carriage in slaughterhouse workers in contact with live pigs in The Netherlands. Epidemiol Infect 2010, 138(5):756-763.

39. de Boer E, Zwartkruis-Nahuis J, Wit B, Huijsdens X, de Neeling A, Bosch T, van Oosterom R, Vila A, Heuvelink A: Prevalence of methicillin-resistant Staphylococcus aureus in meat. Int J Food Microbiol 2008.

40. Weese JS, Avery BP, Reid-Smith RJ: Detection and quantification of methicillin-resistant Staphylococcus aureus (MRSA) clones in retail meat products. Lett Appl Microbiol 2010, 51:338-342.

41. Weese JS, Reid-Smith R, Rousseau J, Avery B: Methicillin-resistant Staphylococcus aureus (MRSA) contamination of retail pork. Can vet $J$ 2010, 51(7):749-752.

42. Huber H, Koller S, Giezendanner N, Stephan R, Zweifel C: Prevalence and characteristics of meticillin-resistant Staphylococcus aureus in humans in contact with farm animals, in livestock, and in food of animal origin, Switzerland, 2009. Euro Surveill 2010, 15(16)

43. van Duijkeren E, Ikawaty R, Broekhuizen-Stins M, Jansen M, Spalburg E, de Neeling A, Allaart J, van Nes A, Wagenaar J, Fluit A: Transmission of methicillin-resistant Staphylococcus aureus strains between different kinds of pig farms. Vet Microbiol 2007.

44. Weese JS, Zwambag A, Rosendal T, Reid-Smith R, Friendship R: Longitudinal Investigation of Methicillin-Resistant Staphylococcus aureus in Piglets. Zoonoses and Public Health 2010.

45. Bidet P, Barbut F, Lalande V, Burghoffer B, Petit J: Development of a new PCR-ribotyping method for Clostridium difficile based on ribosomal RNA gene sequencing. FEMS Microbiol Lett 1999, 175(2):261-266.

46. Kato H, Kato N, Watanabe K, Iwai N, Nakamura H, Yamamoto T, Suzuki K, Kim S, Chong Y, Wasito E: Identification of toxin A-negative, toxin Bpositive Clostridium difficile by PCR. J Clin Microbiol 1998, 36(8):2178-2182.

47. Lemee L, Dhalluin A, Testelin S, Mattrat M, Maillard K, Lemeland J, Pons J: Multiplex PCR targeting tpi (triose phosphate isomerase), tcdA (Toxin A), and $t c d B$ (Toxin B) genes for toxigenic culture of Clostridium difficile. $J$ Clin Microbiol 2004, 42(12):5710-5714.

48. Stubbs S, Rupnik M, Gibert M, Brazier J, Duerden B, Popoff M: Production of actin-specific ADP-ribosyltransferase (binary toxin) by strains of Clostridium difficile. FEMS Microbiol Lett 2000, 186(2):307-312.

49. Rupnik M, Avesani $V$, Janc $M$, von Eichel-Streiber C, Delmée M: A novel toxinotyping scheme and correlation of toxinotypes with serogroups of Clostridium difficile isolates. J Clin Microbiol 1998, 36(8):2240-2247.

50. Mulvey MR, Boyd DA, Gravel D, Hutchinson J, Kelly S, McGeer A, Moore D, Simor A, Suh KN, Taylor G, et al: Hypervirulent Clostridium difficile strains in hospitalized patients, Canada. Emerging Infect Dis 2010, 16(4):678-681.

51. Curry SR, Marsh JW, Muto CA, O'Leary MM, Pasculle AW, Harrison LH: tcdC genotypes associated with severe TcdC truncation in an epidemic clone and other strains of Clostridium difficile. J Clin Microbiol 2007. 45(1):215-221.

52. Shopsin B, Gomez M, Montgomery S, Smith D, Waddington M, Dodge D, Bost D, Riehman M, Naidich S, Kreiswirth B: Evaluation of protein A gene polymorphic region DNA sequencing for typing of Staphylococcus aureus strains. J Clin Microbiol 1999, 37(11):3556-3563.

53. Rankin S, Roberts S, O'Shea K, Maloney D, Lorenzo M, Benson C: Panton valentine leukocidin (PVL) toxin positive MRSA strains isolated from companion animals. Vet Microbiol 2005, 108(1-2):145-148.

54. Martin H, Willey B, Low DE, Staempfli HR, McGeer A, Boerlin P, Mulvey M, Weese JS: Characterization of Clostridium difficile Strains Isolated from Patients in Ontario, Canada, from 2004 to 2006. I Clin Microbiol 2008, 46(9):2999-3004

55. Hoffer E, Haechler H, Frei R, Stephan R: Low occurrence of Clostridium difficile in fecal samples of healthy calves and pigs at slaughter and in minced meat in Switzerland. J Food Prot 2010, 73(5):973-975.

56. Khalid KA, Zakaria Z, Toung OP, McOrist S: Low levels of meticillin-resistant Staphylococcus aureus in pigs in Malaysia. Vet Rec 2009, 164(20):626-627.

57. Rodriguez-Palacios A, Staempfli H, Duffield T, Weese J: Clostridium difficile in retail ground meat, Canada. Emerging Infect Dis 2007, 13(3):485-487.

58. Pu S, Han F, Ge B: Isolation and characterization of methicillin-resistant Staphylococcus aureus strains from Louisiana retail meats. Appl Environ Microbiol 2009, 75(1):265-267.

59. van Loo IH, Diederen BM, Savelkoul PH, Woudenberg JH, Roosendaal R, van Belkum A, Lemmens-den Toom N, Verhulst C, van Keulen PH, Kluytmans JA: Methicillin-resistant Staphylococcus aureus in meat products, the Netherlands. Emerging Infect Dis 2007, 13(11):1753-1755.

60. Warny M, Pepin J, Fang A, Killgore G, Thompson A, Brazier J, Frost E, McDonald L: Toxin production by an emerging strain of Clostridium difficile associated with outbreaks of severe disease in North America and Europe. Lancet 2005, 366(9491):1079-1084.

61. Hasman H, Moodley A, Guardabassi L, Stegger M, Skov R, Aarestrup F: spa type distribution in Staphylococcus aureus originating from pigs, cattle and poultry. Vet Microbiol 2009, 141:326-331.

62. Christianson S, Golding G, Campbell J, Mulvey M: Comparative genomics of Canadian epidemic lineages of methicillin-resistant Staphylococcus aureus. J Clin Microbiol 2007, 45(6):1904-1911.

63. Tenover FC, McAllister S, Fosheim G, McDougal LK, Carey RB, Limbago B, Lonsway D, Patel JB, Kuehnert MJ, Gorwitz R: Characterization of Staphylococcus aureus isolates from nasal cultures collected from individuals in the United States in 2001 to 2004. J Clin Microbiol 2008, 46(9):2837-2841.

64. van Duijkeren $E$, Jansen MD, Flemming SC, de Neeling $H$, Wagenaar JA, Schoormans AH, van Nes A, Fluit AC: Methicillin-resistant Staphylococcus aureus in pigs with exudative epidermitis. Emerging Infect Dis 2007, 13(9):1408-1410

65. Golding GR, Bryden L, Levett PN, McDonald RR, Wong A, Wylie J, Graham MR, Tyler S, Van Domselaar G, Simor AE, et al: Livestock-associated methicillin-resistant Staphylococcus aureus sequence type 398 in humans, Canada. Emerging Infect Dis 2010, 16(4):587-594.

doi:10.1186/1746-6148-7-41

Cite this article as: Weese et al: Clostridium difficile and methicillinresistant Staphylococcus aureus shedding by slaughter-age pigs. BMC Veterinary Research 2011 7:41

\section{Submit your next manuscript to BioMed Central and take full advantage of:}

- Convenient online submission

- Thorough peer review

- No space constraints or color figure charges

- Immediate publication on acceptance

- Inclusion in PubMed, CAS, Scopus and Google Scholar

- Research which is freely available for redistribution

Submit your manuscript at www.biomedcentral.com/submit
C Biomed Central 